\title{
Adenosine 5'-triphosphate and its relationship with other mediators that activate pelvic nerve afferent neurons in the rat colorectum
}

\author{
Gregory Wynn \& Geoffrey Burnstock \\ Autonomic Neuroscience Centre, Royal Free and University College School of Medicine, Rowland Hill Street, \\ London, NW3 $2 P F, U K$
}

Received 23 September 2005; accepted in revised form 18 November 2005; Published online 16 August 2006

Key words: 5-HT, ATP, bradykinin, capsaicin, protons, sensory nerves, synergism

\begin{abstract}
Evidence of a role for purinergic signalling in visceral afferents involving $\mathrm{P} 2 \mathrm{X}_{2}, \mathrm{P} 2 \mathrm{X}_{3}$ and $\mathrm{P} 2 \mathrm{Y}_{1}$ receptors exists, which appears to be important during inflammation. This study aimed to evaluate the degree of interaction between adenosine $5^{\prime}$-triphosphate (ATP) and other mediators that activate sensory nerves in the colorectum. Recordings from pelvic nerve afferents were made during application of agents to the in-vitro colorectal preparation. Analysis allowed calculation of single unit activity. When applied individually, bradykinin (78\%) and 5-hydoxytryptamine (77\%) activated the greatest number of neurons, followed by substance P, protons, ATP and capsaicin. Prostaglandin $\mathrm{E}_{2}$ stimulated the least number (54\%) and had a longer latency. Seventy-seven percent of all units studied either responded to both ATP and capsaicin or to neither, giving the greatest degree of activity correlation. Five percent of units were activated by all seven agents and no units were activated by a single agent alone. 5-hydroxytryptamine, capsaicin and protons, when co-applied with ATP, increased pelvic nerve activity to a greater degree than the sum of the individual responses. It is concluded that ATP activates pelvic nerve afferents and acts synergistically with protons, capsaicin and 5-hydroxytryptamine. The pattern of neuronal activation suggests that visceral afferents are polymodal but the receptor expression on their terminals is variable.
\end{abstract}

Abbreviations: $\alpha, \beta$-meATP- $\alpha, \beta$-methylene ATP; 5-HT-5-hydroxytryptamine; ATP-adenosine 5 -triphosphate; $\mathrm{BK}$ - bradykinin; $\mathrm{DRG}$ - dorsal root ganglion; $\mathrm{PGE}_{2}$ - prostaglandin $\mathrm{E}_{2}$; $\mathrm{SP}$ - substance $\mathrm{P}$; UTP - uridine $5^{\prime}$-triphosphate

\section{Introduction}

Evidence of a role for purinergic signalling in sensory neurons is well-established [1]. $\mathrm{P} 2 \mathrm{X}_{2}$ and $\mathrm{P} 2 \mathrm{X}_{3}$ receptors, two members of the larger P2X family of ligand-gated cation channels, are important in this process because both are expressed in sensory ganglia. $\mathrm{P} 2 \mathrm{X}_{3}$ receptors are selectively expressed on a subpopulation of small diameter sensory neurons in dorsal root ganglia (DRG), most of which label for the isolectin IB4 [2]. $\mathrm{P}_{2} \mathrm{X}_{2}$ receptors, also present in $\mathrm{DRG}$, are $\mathrm{pH}$ sensitive and along with $\mathrm{P} 2 \mathrm{X}_{3}$ subunits can form heteromultimers that yield adenosine $5^{\prime}$ triphoshate (ATP)-activated currents similar to those found in sensory neurons [3]. Metabotropic $\mathrm{P}_{2} \mathrm{Y}_{1}$ and $\mathrm{P} 2 \mathrm{Y}_{4}$ receptors have been demonstrated on a subpopulation of DRG neurons that also express $\mathrm{P}_{2} \mathrm{X}_{3}$ receptors [4].

A working hypothesis of purine-mediated mechanosensory transduction has been proposed [5]. ATP released during distension from epithelial cells lining tubes (such as

Correspondence to: Dr Geoffrey Burnstock, Autonomic Neuroscience Centre, Royal Free and University College School of Medicine, Rowland Hill Street, London, NW3 2PF, UK. Tel: +44-(0)20-78302948; Fax: +44(0)20-78302949; E-mail: g.burnstock@ucl.ac.uk ureter or gut), and sacs (such as bladder), acts on $\mathrm{P}_{2} \mathrm{X}_{3}$ and/ or $\mathrm{P} 2 \mathrm{X}_{2 / 3}$ receptors on a subepithelial sensory nerve plexus to initiate impulses that are relayed to the central nervous system via extrinsic spinal afferents such as the pelvic nerve. Work in our laboratory has suggested that this mechanism contributes to afferent signalling during distension of the mouse bladder [6] and guinea pig ureter [7] and colorectal distension in the rat [8]. In the latter study, we demonstrated that ATP release from colorectal epithelial cells was pressure-dependent and that exogenous ATP activated the same afferent fibres in the pelvic nerve that were stimulated by noxious distension. In addition, about $25 \%$ of the distension-evoked pelvic nerve discharge could be blocked with P2X receptor antagonists. It is clear that other agents therefore play an important role in mechanosensory transduction during distension in the normal colorectum.

The relative importance of agents involved in signalling gut distension may change according to the physiological and pathophysiological conditions present. The gastrointestinal mucosa is known to release a whole host of different mediators in a wide range of situations [9-13] and especially during inflammation [14]. It is in pathophysiological states such as this that complex interactions gov- 
erning the response to tissue injury are critical. Many studies have implicated ATP as particularly important in the inflammatory setting [15-17] and this correlates with the fact that ATP is present intracellularly in millimolar concentrations making it a good candidate for signalling significant tissue damage. In fact, recent work in our laboratory has indicated that release of ATP from the colorectal mucosa and sensory nerve discharges evoked by ATP are significantly increased during colitis [18]. It is possible that ATP may interact with some of these mediators and/or modulate their effect on extrinsic enteric neurons.

The present study was designed to investigate the correlation of ATP-sensitive pelvic nerve fibres with sensitivity to a range of other important agents that are known to stimulate extrinsic afferent neurons in the gut. An established in-vitro model [8] was used to study changes in net afferent traffic in spinal nerves in response to rises in the tissue concentration of one or more mediators. This study does not tell us about the precise mechanisms via which neurons in the enteric nervous system are stimulated but does give us a measure of extrinsic afferent signalling to the central nervous system of which pain must be a component.

\section{Materials and methods}

\section{Animals}

Experiments were performed using adult male and female Sprague-Dawley rats (240-320 g) that were allowed free access to food and water. Animals were humanely sacrificed by exposure to rising levels of carbon dioxide and cervical dislocation in accordance with UK Animals (Scientific Procedures) Act 1986, covering Schedule One procedures.

\section{Electrophysiology}

The distal colon and rectum were dissected from the pelvis with attached pelvic nerve and placed in a $10 \mathrm{ml}$ bath at room temperature superfused with oxygenated Krebs solution (contents in mM: $\mathrm{NaCl} 120 ; \mathrm{KCl} 5.9 ; \mathrm{NaH}_{2} \mathrm{PO}_{4}$ 1.2; $\mathrm{MgSO}_{4}$ 1.2; $\mathrm{NaHCO}_{3}$ 15.4; $\mathrm{CaCl}_{2}$ 2.5; Glucose 11.5; $\mathrm{pH}$ 7.4). Both proximal and distal ends of the $30 \mathrm{~mm}$ length of bowel were secured to $8.5 \mathrm{Fr}$. three-way cannulae and the lumen perfused with Krebs solution. Ports on the cannulae were connected to a pressure transducer, drainage tubing (which was only clamped during distensions) and infusion tubing, which was connected in turn to a syringe driver (sp210iw; World Precision Instruments, Sarasota, FL). Following careful dissection of the pelvic nerve under the microscope into small branches, multifibre afferent activity was recorded using a suction glass electrode (tip diameter $50-100 \mu \mathrm{m})$ connected to a Neurolog headstage (NL 100; Digitimer Ltd, UK) and an AC amplifier (NL 104). Signals were amplified $(\times 10,000)$, filtered (NL 125 , band pass $200-4,000 \mathrm{~Hz}$ ) and captured by a computer via a power 1401 analogue-to-digital interface and Spike 2 software (version 4.03, Cambridge Electronic Design, UK). In all cases, the tissues were allowed to stabilise in the bath for $60 \mathrm{~min}$ before gathering data. Those branches that did not yield a good response to distension were not used. Control distensions to $50 \mathrm{mmHg}$ with Krebs were repeated at 10-min intervals until nerve responses were stable. Applications of the various mediators were applied as a fast $10 \mathrm{ml}$ bolus less than $10 \mathrm{~mm}$ away from the serosal surface of the colorectum and left to stagnate in the bath until activity had reduced to baseline levels. When dye was used in this manner, no discolouration was seen in the luminal fluid. Drug concentrations were decided upon by prior experimental dose-response data in our colorectal preparation.

During analysis of the multifibre recordings, single unit recordings were extracted by the Spike2 software (Cambridge Electronic Design, Cambridge, UK). Advice from the manufacturers was taken in trying to get the most sensitive discriminatory settings. Template parameters were set as follows: number of similar spikes for a new template $=10$; new template width as a percentage of amplitude $=25$; no template for shapes rarer than 1 in 50; maximum percent amplitude change for match $=20$; minimum percentage of points in template $=80$ (only used during template building); template modification mode $=$ add all; waveform interpolation method $=$ linear; high pass filter time constant $=$ two to three times the spike width; DC offset was removed. We have analysed the difference between small $(<12$ units) and larger $(>12$ units) recordings to find out if the percentage of units responding to a given agent were different in the two groups at the same discriminatory settings. This revealed that the variability in the size of the pelvic nerve bundles used in these experiments did not significantly alter the results.

The results for all experiments are presented as mean \pm standard error of the mean (SEM). Data was compared by Student's $t$-test and analysis of variance unless otherwise stated and differences considered statistically significant at $P<0.05$.

\section{Chemicals}

ATP (disodium salt), bradykinin (BK), capsaicin, 5-HT, $\mathrm{PGE}_{2}$ and SP were all obtained from Sigma, Poole, UK. All chemicals were diluted in Krebs solution to required concentrations before use. Titration of concentrated hydrochloric acid in Krebs solution was used to provide the correct $\mathrm{pH}$ in the relevant experiments.

\section{Results}

\section{Pelvic nerve responses to ATP and other agents}

Figure 1 demonstrates typical examples of pelvic nerve activity in response to bolus applications of a variety of neuro- 


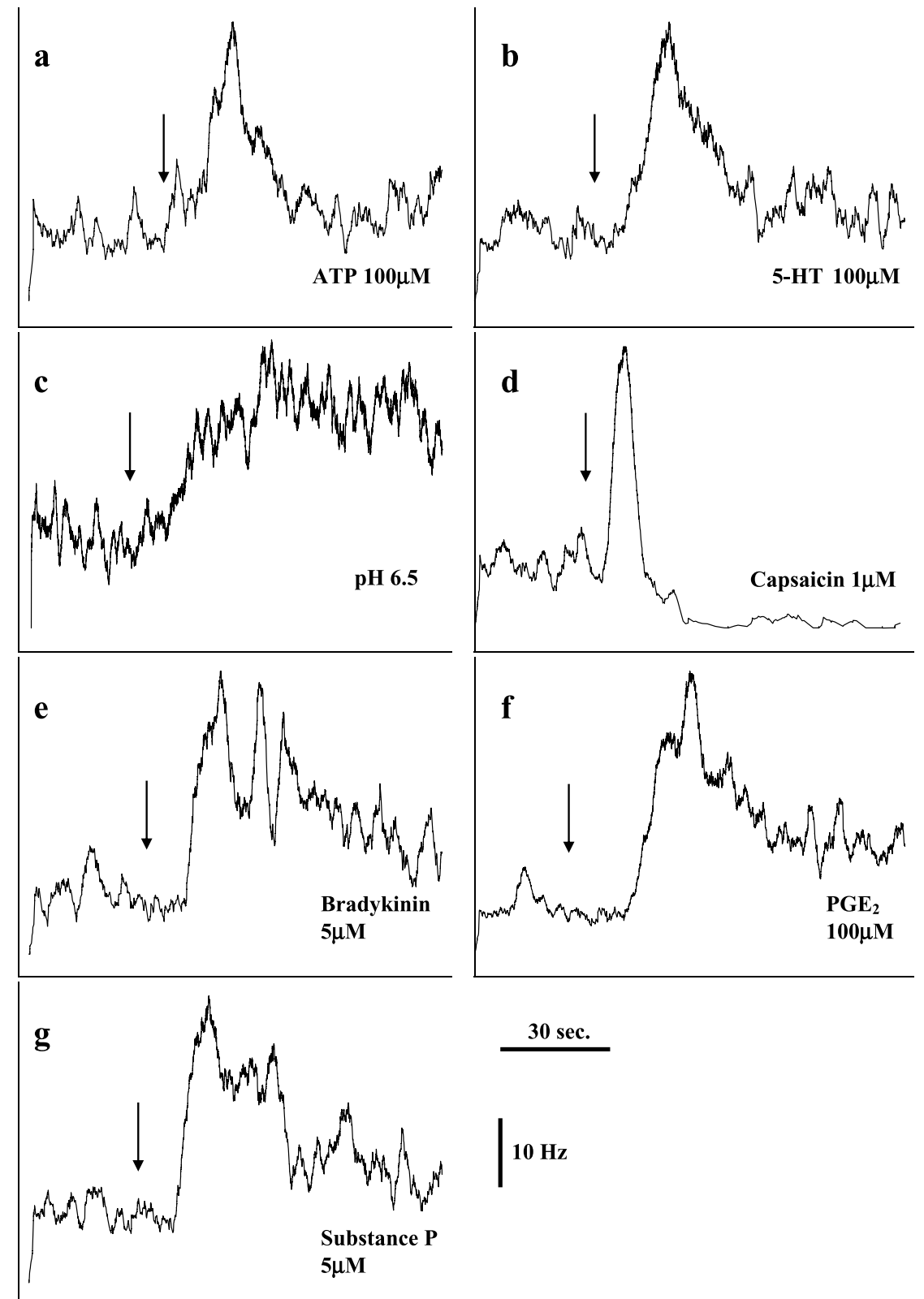

Figure 1. Typical responses from pelvic nerve afferents during application of the various agents used in the study. The traces show the frequency of spike firing (Hz) during multifibre recording. As labelled, the responses to (a) ATP, (b) 5-HT, (c) protons, (d) capsaicin, (e) bradykinin, (f) prostaglandin $\mathrm{E}_{2}$ and $(\mathrm{g})$ substance $\mathrm{P}$ are shown. Arrows denote point of application.

active mediators applied to the serosal surface of the colorectum at the concentrations shown. Each individual trace is of 2 min duration and represents the increase in spike frequency during a multifibre recording. ATP and 5-HT produced very similar frequency plots, as did BK and SP. Capsaicin activated the extrinsic afferents with the shortest latency $(5.47 \pm 1.7 \mathrm{~s} ; n=5$, see Figure 2a) and reached peak activity after a mean period of just $11.8 \pm 1.3 \mathrm{~s} ; n=5$ (see Figure $2 b$ ). This was typically followed by a sharp fall in the frequency of spikes and a period of desensitisation where nerve activity fell to almost zero but recovered after several minutes, depending on the concentration used. Concentrations of $50 \mu \mathrm{M}$ or more usually ensured that nerve activity never fully recovered. Figure 2 a shows that there was no significant difference in the pelvic nerve activation latencies of capsaicin, ATP, 5-HT, BK, SP or protons, but $\mathrm{PGE}_{2}$ took longer to excite the nerve above baseline levels and to reach its maximum firing frequency (Figure 2b).

Single unit analysis (using Spike 2 software) revealed how many individual units were being recorded and which units were responding to particular agents (and distension). Previous analysis had shown that resting activity in the same unit did not vary by more than $10 \%$. This allowed an assumption that any activity of over $10 \%$ of the mean resting frequency of a unit during the first $60 \mathrm{~s}$ after application of an agent would represent a response. Fortyfour different experiments were carried out in 26 in vitro 

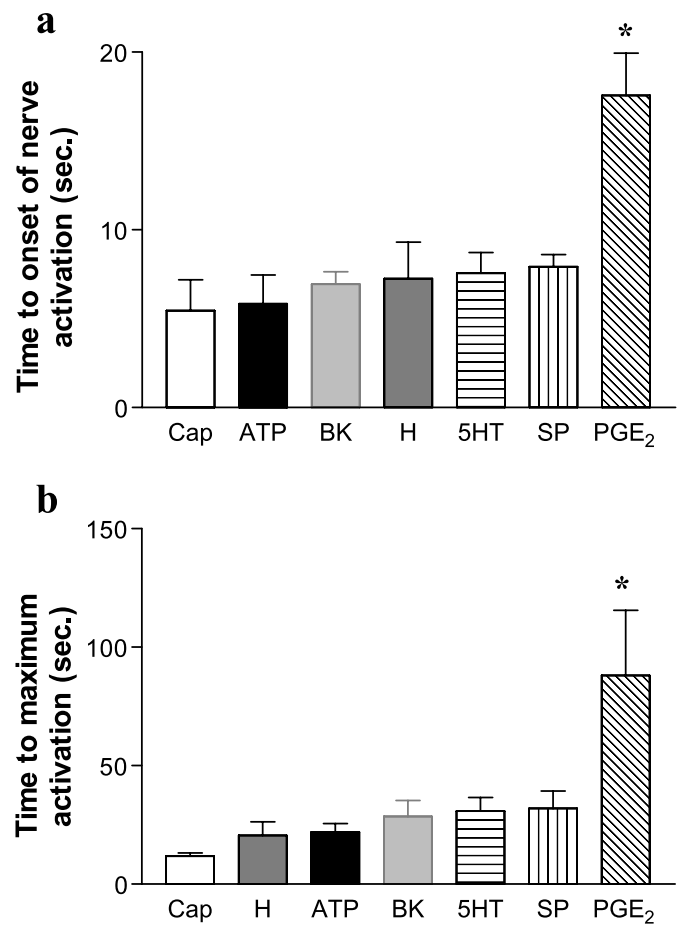

Figure 2. The latencies of activation of the agents applied to the serosal surface of the colorectum were similar except for prostaglandin $E_{2}$ (a). The time taken to reach peak spike frequency is shown in (b), where capsaicin was fastest and prostaglandin substantially slower than the others (cap, capsaicin; $\mathrm{H}$, protons). ${ }^{*} P \leq 0.05$.

preparations and a total of 674 individual units were analysed. Each recording had an average of 15 units. Because it was possible that the number of units per recording might affect the accuracy of the results, a representative sample of responses to ATP were compared in recordings that contained less than 12 units and those that contained more than this. In the smaller recordings, $71 \pm 0.05 \%$ of units responded to ATP $(n=14)$. In the larger recordings, $66 \pm 0.03 \%$ responded to ATP $(n=24)$. The difference between these two groups was not significant $(P=0.384)$. In total, application of ATP to the colorectal preparation resulted in activation of 440 of the 674 units studied (65\%). Table 1 shows the percentage of units that responded to the other various stimuli. The rank order of agents activating the most units was: $\mathrm{BK} \geq 5$-HT $>\mathrm{SP}>$ Protons $>$ ATP $>$
Capsaicin $>\mathrm{PGE}_{2}$. In the experiments that involved phasic colorectal distension to $50 \mathrm{mmHg}$, this stimulus activated 178 out of 188 units studied (95\%). This result was clearly not representative of the entire pelvic nerve but of an area that consistently responded to colorectal distension which was used for all the experiments. A typical response to colorectal distension from this part of the nerve is shown in Figure 3.

When ATP was applied in the same experiment as other agents, it was possible to establish which units each agent activated (see Table 1). The most common agent (that was tested) to activate ATP-responsive units was 5-HT (61\% of units). Ninety percent of all units responded to either ATP or 5-HT but about a sixth of these responded to 5-HT only and a further sixth to ATP only giving a two-thirds overlap between the populations. BK activated the largest percentage of units overall (78\%) but over a fifth of these (21\%) were unresponsive to ATP. The percentage of units responding to ATP as well as substance P, capsaicin and a lowered $\mathrm{pH}$ was very similar (just over half) and the proportion responding to ATP only was similar for these agents also. The main difference between these three agents was their ability to activate units that were unresponsive to ATP. SP achieved this in $21 \%$ of cases, protons in $16 \%$ and capsaicin in just $8 \%$. In fact, $77 \%$ of all units either responded to both ATP and capsaicin or to neither, giving the greatest degree of correlation between ATP and any of the agents applied. In the units that responded to both ATP and capsaicin, ATP was able to stimulate activity after the application of capsaicin $1 \mu \mathrm{M}$ had reduced the background firing to almost zero (Figure 4). This excitation of capsaicinsensitive units occurred in all the units that were initially responsive to the control bolus of ATP, although the frequency of spikes in these units was substantially reduced during the desensitisation period. $\mathrm{PGE}_{2}$ activated the smallest percentage of units overall (54\%) and alongside SP had the lowest activity correlation with ATP (65\%).

In two experiments, all the agents were applied in turn with at least half an hour washout between each one. Only $5 \%$ of units were activated by all seven agents, as well as distension, whereas no units were activated by a single agent alone. Raising the concentration of the agent increased the frequency of spikes in individual units but didn't significantly alter the latency of activation or the percentage of units responding.

Table 1. The percentage of pelvic nerve fibres that are responsive to the various agents applied to the colorectum is shown (column 2) along with the degree of overlap between ATP-activated units and those activated by the various other agents.

\begin{tabular}{|c|c|c|c|c|c|}
\hline Agent & $\begin{array}{l}\text { Number of units studied } \\
\text { (\% responding to stimulus) }\end{array}$ & $\begin{array}{l}\text { Units responding to } \\
\text { both ATP and agent }\end{array}$ & $\begin{array}{l}\text { Units responding to neither } \\
\text { ATP nor agent }\end{array}$ & $\begin{array}{l}\text { Units responding to } \\
\text { agent but not to ATP }\end{array}$ & $\begin{array}{l}\text { Units responding to } \\
\text { ATP but not to agent }\end{array}$ \\
\hline 5-HT & $131(77 \%)$ & $80(61 \%)$ & $13(10 \%)$ & $21(16 \%)$ & $17(13 \%)$ \\
\hline Bradykinin & $219(78 \%)$ & $125(57 \%)$ & $38(17 \%)$ & $46(21 \%)$ & $10(5 \%)$ \\
\hline Protons & $68(69 \%)$ & $36(53 \%)$ & $12(18 \%)$ & $11(16 \%)$ & $9(13 \%)$ \\
\hline Capsaicin & $89(60 \%)$ & $46(52 \%)$ & $22(25 \%)$ & $7(8 \%)$ & $14(15 \%)$ \\
\hline Substance P & $95(73 \%)$ & $50(52 \%)$ & $12(13 \%)$ & $20(21 \%)$ & $13(14 \%)$ \\
\hline $\mathrm{PGE}_{2}$ & $72(54 \%)$ & $31(43 \%)$ & $16(22 \%)$ & $8(11 \%)$ & $17(24 \%)$ \\
\hline
\end{tabular}




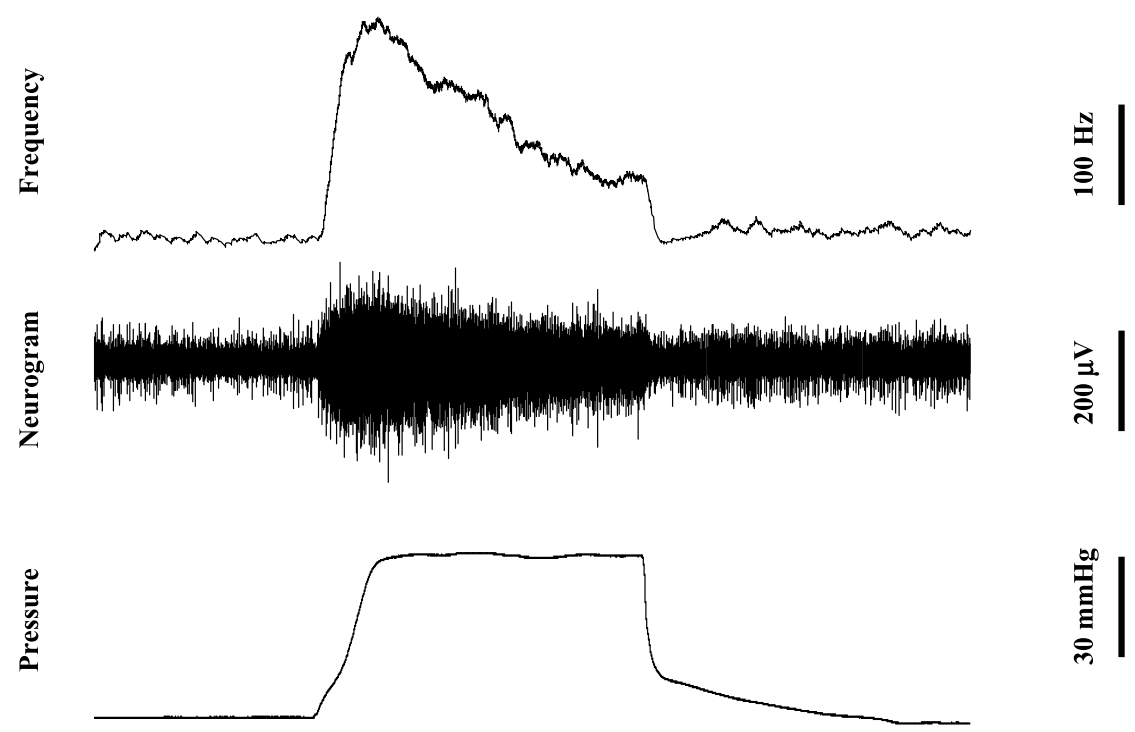

Figure 3. A typical response of a pelvic nerve multiunit recording to distension $(50 \mathrm{mmHg})$.

Interactions between ATP and other agents

The influence of ATP on the activation of colorectal extrinsic afferents by the various agents was investigated by applying the transmitters alone or together with ATP. A low concentration of either ATP or the agent to be tested was applied to the colorectal serosa and after a 30-min washout, a high dose of the mediator not used initially was applied. Both were then applied simultaneously in the same concentrations following a further lengthy washout period. The concentrations (and therefore the order of application) were then reversed.

When ATP $(50 \mu \mathrm{M}$ or $1 \mathrm{mM})$ was applied simultaneously with either BK $(100 \mathrm{nM}$ or $5 \mu \mathrm{M}), \mathrm{PGE}_{2}(1 \mu \mathrm{M}$ or $10 \mu \mathrm{M})$ or $\mathrm{SP}(1 \mu \mathrm{M}$ or $10 \mu \mathrm{M})$, all had non-additive effects. The size of the combined response was always greater than either of the individual responses but smaller than the sum of the two. This was the case regardless of the order of application or concentration. In contrast, the combined responses of ATP with either 5-HT, capsaicin or lowered $\mathrm{pH}$ were greater than the sum of their individual responses and examples of these three experiments are shown in Figure 5(a)-(c), respectively. 5-HT (5 or 100 $\mu \mathrm{M})$ applied with ATP (1 $\mathrm{mM}$ or $50 \mu \mathrm{M}$, respectively) resulted in an overall increase in spike frequency of $19.4 \pm$ $9.8 \%(n=8)$ over the sum of the individual components and this was statistically significant $(P=0.05$; see Figure 6a). There was no significant difference between the two experimental conditions relating to the concentrations of the agents: 5-HT $5 \mu \mathrm{M}$ and ATP $1 \mathrm{mM}$ gave an increase of $17.7 \pm 10.2 \%$ whereas ATP $50 \mu \mathrm{M}$ added to 5 -HT $100 \mu \mathrm{M}$ resulted in an increase of $21.0 \pm 16.7 \%$. When low concentration capsaicin $(100 \mathrm{nM})$ was applied together with ATP $1 \mathrm{mM}$ (a high dose of capsaicin could not be used due
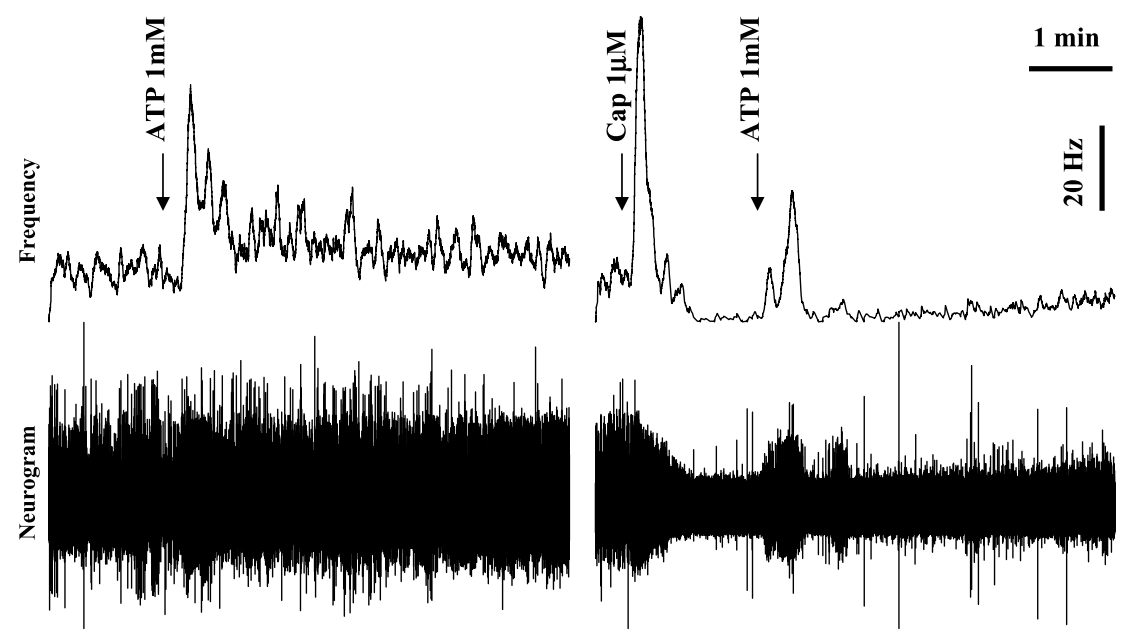

Figure 4. Two continuous traces from the same experiment are shown. On the left, the pelvic nerve (multifibre) response to application of ATP $1 \mathrm{mM}$ to the colorectum is demonstrated. On the right (after $30 \mathrm{~min}$ washout) the response to capsaicin (Cap) $1 \mu \mathrm{M}$ is shown, followed shortly afterwards by a repeat application of ATP $1 \mathrm{mM}$. The ATP-sensitive fibres are still responsive after capsaicin, but multifibre activity is reduced compared to the previous application of ATP. Top trace: spike frequency $(\mathrm{Hz})$, bottom trace: neurogram. 


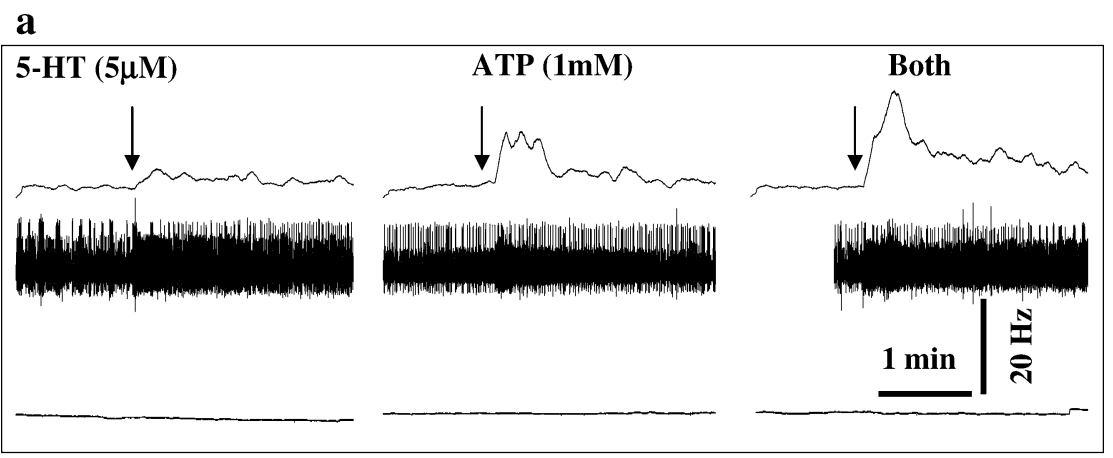

b
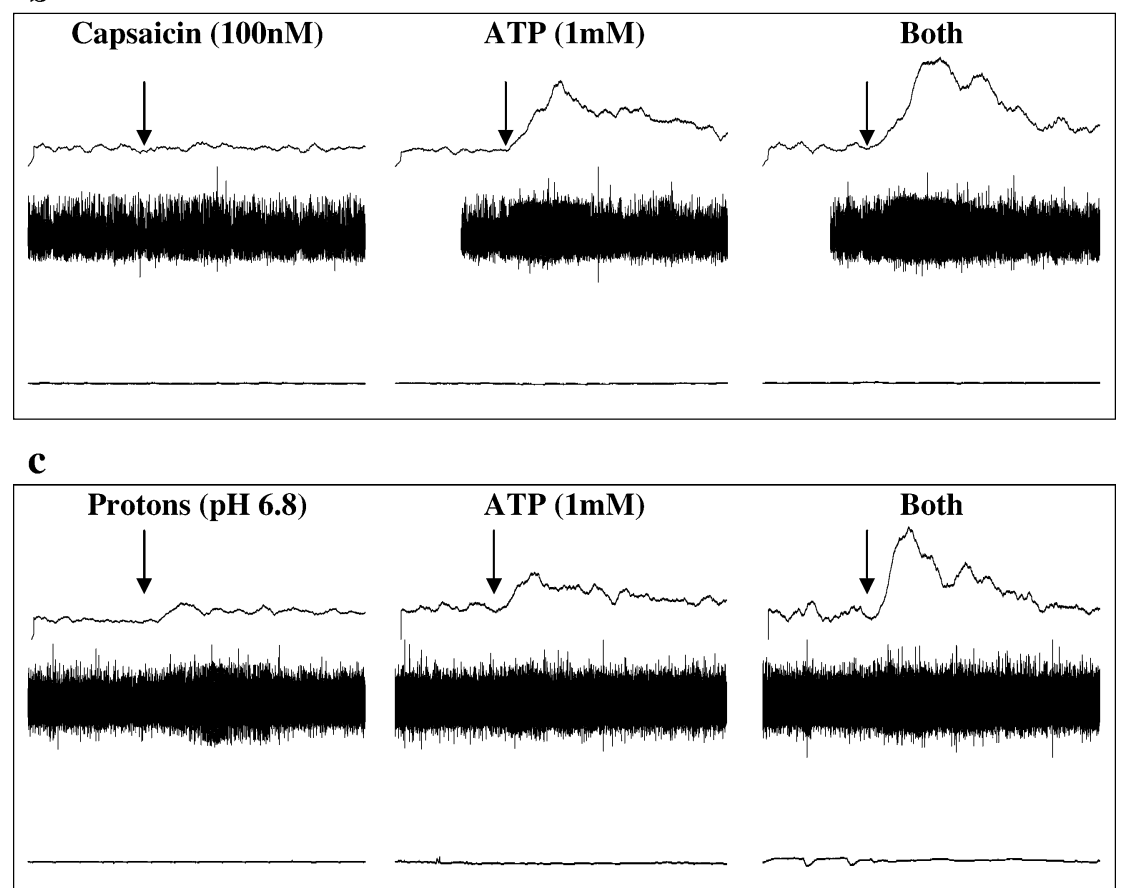

Figure 5. Pelvic nerve recordings are shown during the application of 5-HT (a), capsaicin (b) and protons (c). For each experiment, three traces are shown: the top trace shows the frequency of activity, the middle trace the neurogram and the bottom line shows the pressure, which remained at zero throughout. The figures show the application of low concentration agent (left hand traces), followed by ATP 1 mM (middle traces) and then the coapplication of both (right hand traces) showing greater activity than the sum of the two individual responses.

to its neurotoxicity), the frequency of spikes was increased by $25.9 \pm 8.7 \%(n=8)$ compared with the sum of the individual responses $(P=0.018$; Figure 6b). Application of ATP in the presence of a lowered $\mathrm{pH}$ gave the most striking results. At $\mathrm{pH} 6.8$, the response to ATP $1 \mathrm{mM}$ was increased by $40.3 \pm 3.1 \%(n=4$; see Figure $6 \mathrm{c})$ above the sum of the individual responses $(P<0.0001)$, whereas at $\mathrm{pH} 6.5$ this increase had risen to $72.6 \pm 4.1 \%(n=4 ; P<$ 0.0001; see Figure 6d). Changing the concentration of ATP altered the magnitude of the response to the control bolus and the combined response at a given $\mathrm{pH}$, but the degree of increase above the sum of the individual responses could only be affected by the concentration of protons.

\section{Analysis of single units contributing to the increased responses seen by combined application}

By studying the spike frequency of individual units during the application of one or more agents, it was possible to evaluate which units were contributing to the increased response of the nerve as a whole. The vast majority of units that contributed to a greater combined response were activated by both agents, but this was not exclusively the case. In the experiments involving 5-HT, $24 \%$ of units increased their firing frequency sufficiently in the presence of a combined bolus of ATP and 5-HT to surpass the responses of both single boluses put together. Of these, three quarters were activated by both single applications and a quarter of them by ATP only. None of the units studied were activated by 5-HT only and then went on to contribute to the increased response. An example of a single unit that contributed to the increased response when both agents were applied is shown in Figure 7. In this case, both ATP and 5-HT activated the unit. Thirty-one percent of units contributed to the combined increased response seen with ATP and capsaicin. All of these units were activated by both single applications. In the experiments involving ATP and protons, the larger combined response 

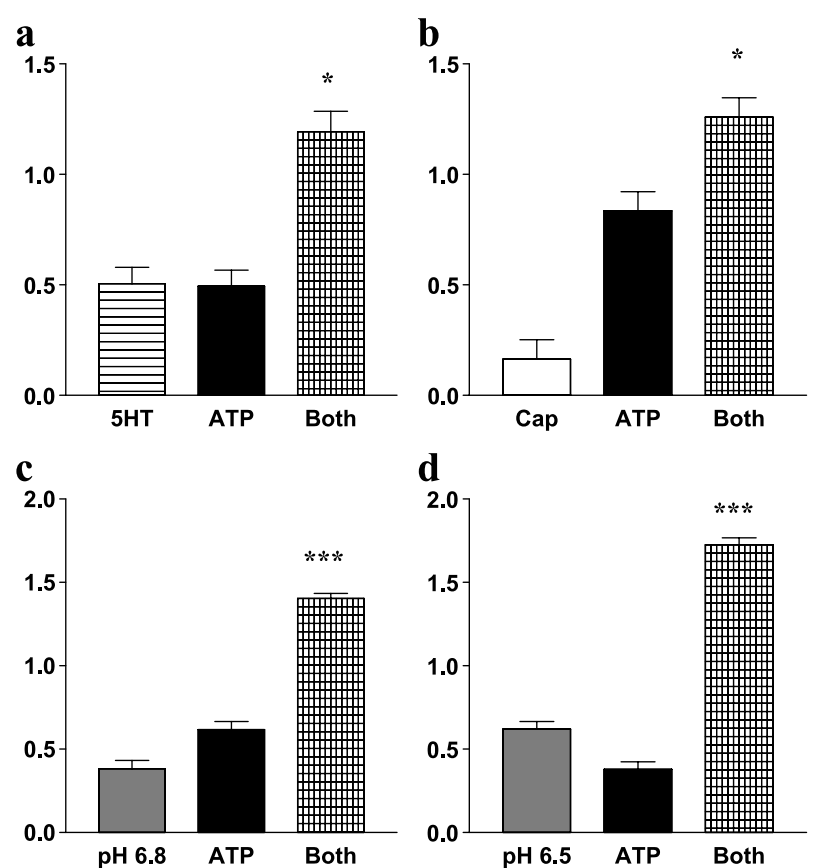

Figure 6. (a) Co-application of 5-HT (5 or $100 \mu \mathrm{M})$ and ATP ( $1 \mathrm{mM}$ or $50 \mu \mathrm{M}$, respectively) resulted in greater nerve activity than the sum of the individual responses suggesting synergism (combined data for high and low concentrations is shown). This was also the case for low concentration data capsaicin (Cap) $100 \mathrm{nM}$ and ATP $1 \mathrm{mM}$ (b). Responses to ATP $1 \mathrm{mM}$ are greater at $\mathrm{pH} 6.8(\mathbf{c})$ and even more so at $\mathrm{pH} 6.5$ (d). For each graph, the relative proportion of the sum of the individual responses is shown, so the first two bars add up to 1.0. The third bar (on the right) then demonstrates the degree of increased activity when the two agents are applied together. $* P \leq 0.05 ; * * * P<0.0001$.

was mediated by those units responding to both agents or to protons alone; units exclusively activated by ATP did not contribute. The contribution of units activated by both ATP and protons was only slightly greater at $\mathrm{pH} 6.5$ (34\%) than $\mathrm{pH} 6.8$ (32\%). However, those responding to protons alone contributed to a greater extent at the lower pH: a further $12 \%$ of units at $\mathrm{pH} 6.8$ but a further $21 \%$ at $\mathrm{pH}$ 6.5. This amounted to a total of $44 \%$ of units at $\mathrm{pH} 6.8$ and $55 \%$ of units at $\mathrm{pH} 6.5$ that made a contribution to the increased response to a combined bolus of ATP and protons.

\section{Discussion}

This study has demonstrated that ATP, protons, capsaicin, 5-HT, BK, SP and $\mathrm{PGE}_{2}$ can activate colorectal extrinsic afferents in the rat pelvic nerve and examples have been given of the typical characteristics of each response. For the first time, a large number of spinal afferent nerve fibres have been analysed with particular reference to ATP, documenting important data relating to the overlap of responsiveness between ATP and other agents. These experiments showed that $95 \%$ of the pelvic nerve afferents studied were responsive to colorectal distension to 50 $\mathrm{mmHg}$, thus providing data from neurons that are specifically involved with the processing of noxious events from this region of the gut. The study strongly suggests that there may be interactions between different signalling systems involved in colorectal afferent activation. We have selected a representative sample of the mediators that are known to stimulate extrinsic enteric neurons and this forms an incomplete picture of visceral afferent stimulation. However, the agents have been chosen because they demonstrate the diversity of mediators that are active in the colorectum, all of which have been implicated in visceral pain.

In the experiments where all the agents were applied in turn, no unit was activated by a single agent and only a tiny proportion was activated by all the agents. Along with the different percentages of units being stimulated by the different agents, this clearly shows that there are marked variations in the sensitivities of visceral neurons. BK and 5-HT were able to stimulate the greatest number of afferent units in this study (78 and $77 \%$, respectively) and these figures are slightly higher than previous studies have suggested. Longhurst et al. [19] calculated that $65 \%$ of visceral afferent fibres responded to BK, although these recordings were made from splanchnic nerves in the cat and were from a wider source than the colorectum. Hicks et al. [20] reported that $56 \%$ of lumbar splanchnic nerve fibres from the rat colorectum responded to 5-HT and this figure rose to over $60 \%$ in the splanchnic nerve of the cat [21]. In rat DRG neurons that supply the pelvic viscera, $70 \%$ were capsaicin sensitive [22] compared to just $30 \%$ of vagal
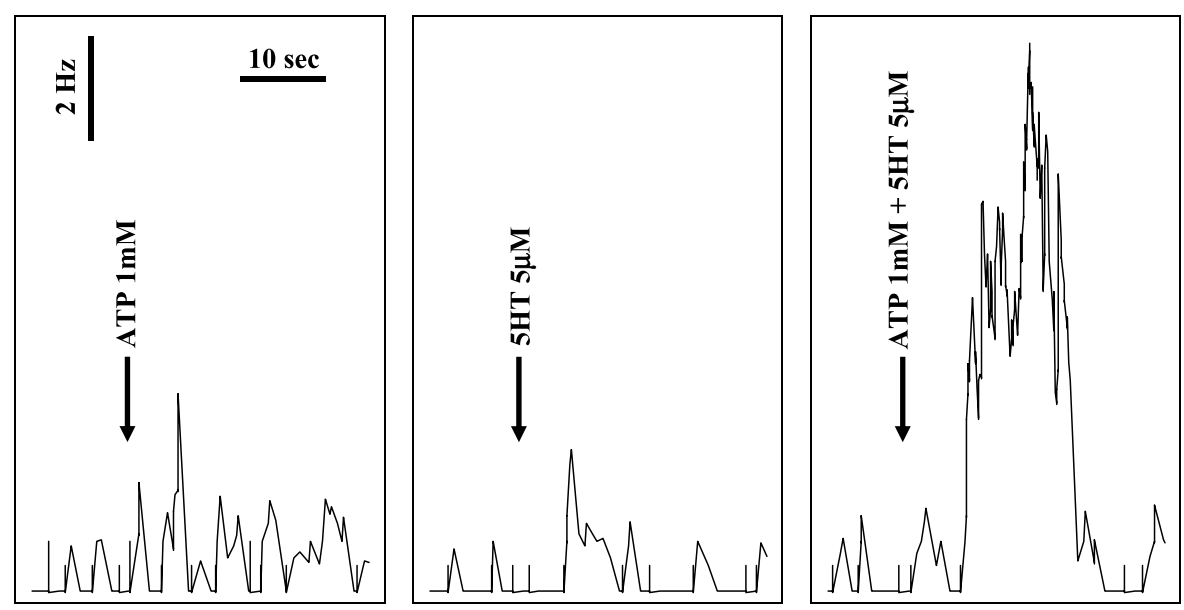

Figure 7. An example of a single unit in the pelvic nerve that responds to both 5-HT and ATP individually. When the two mediators are applied together, the activity is greatly increased. 
fibres innervating the ferret gastrointestinal tract [23]. In another study, $\mathrm{PGE}_{2}$ was found to excite $38 \%$ of rat DRG neurons in culture [24]. When evaluating the number of afferent neurons responding to ATP, again, studies looking at both receptor expression and activation of neurons can be used. $\mathrm{P} 2 \mathrm{X}_{3}$ receptors are expressed on about a third of DRG neurons, nearly all of them small diameter [2], but there are also other populations of DRG neurons that express $\mathrm{P} 2 \mathrm{X}_{2 / 3}, \mathrm{P} 2 \mathrm{X}_{2}$ and $\mathrm{P} 2 \mathrm{X}_{1}$ receptors [25] as well as $\mathrm{P} 2 \mathrm{Y}$ metabotropic receptors $[4,26]$. In DRG neurons of the mouse, $54 \%$ of $\mathrm{C}$-fibres and a further $12 \%$ of $\mathrm{A} \delta$-fibres (a total of $66 \%$ ) were responsive to the $\mathrm{P} 2 \mathrm{Y}$ receptor agonist, UTP and many of these were also responsive to the selective P2X agonist $\alpha, \beta$-methylene ATP ( $\alpha, \beta$-meATP), indicating coexpression of $\mathrm{P} 2 \mathrm{X}$ and $\mathrm{P} 2 \mathrm{Y}$ receptors on many of these cells [27]. The $65 \%$ of units responsive to ATP in this study may reflect the diversity of purinoceptors on spinal afferent neurons supplying the colorectum. Further electrophysiological experiments with more selective agonists are required to distinguish between these receptor types. On the whole, the percentages of units being activated by the various agents in the present study are consistent with previous experiments. Where there are discrepancies, this might occur due to subtle variations in the receptor expression between the innervation of specific visceral organs, relating to differing function or to the method used to apply the agents. Other studies have used intra-arterial injection [19, 21], whereas we used a bolus application to the organ bath and this in itself may preferentially activate those neurons that supply the serosal surface of the colorectum. It must be remembered that the method used to discriminate units in the pelvic nerve in this study may play a part in these differences (see Materials and methods). It is also likely that some of the agents used would affect smooth muscle tone and indirectly cause activation of mechanosensitive visceral afferents. However, to elucidate the precise indirect mechanisms responsible for stimulation of extrinsic afferent neurons was beyond the scope of this study. What these experiments do show is the end result of spinal nerve activity in response to rises in tissue concentrations of the various agents.

The large proportion of units responsive to 5-HT in this study underlines the importance of this agent in the gut. 5HT is released from enterochromaffin cells [13] and excites extrinsic afferents that supply the colorectum [20]. More specifically, both $5-\mathrm{HT}_{3}$ [28] and 5- $\mathrm{HT}_{4}$ [29] receptors are involved in signalling colorectal distension. Purinergic signalling is also involved in colorectal distension [8] and with $61 \%$ of units responding to both 5-HT and ATP, it is likely that these two systems are functionally cooperative. Co-application of both agents in this experiment resulted in a moderate increase in multifibre activity compared to the sum of the individual responses and although this was not great, the difference did reach statistical significance. Studies on intrinsic enteric sensory neurons have suggested that currents induced by coadministration of both 5-HT and ATP were only as large as the currents induced by the individual agents, although many of these neurons were shown to co-express receptors for both [30]. It is quite possible that extrinsic afferents behave in a different way, as it is these neurons that must signal noxious stimulation such as colorectal distension to the central nervous system. Analysis of the firing of individual units in this study suggested that a quarter of the fibres responding to the agents applied together contributed to the synergism and more interestingly, a quarter of these ( $6 \%$ of the total) were not initially responsive to $5-\mathrm{HT}$. This implies that either these units did not express 5-HT receptors, although their ATP-evoked activity was augmented by 5-HT, or that the application of ATP lowered the threshold of activation of 5-HT receptors that were unresponsive to the initial bolus.

Just over half the units responsive to ATP in this study also responded to capsaicin and $77 \%$ of units responded in the same way to both agents, showing a good deal of functional correlation. Capsaicin is important because it is a potent agonist at the TRPV1 receptor, which is expressed on small diameter extrinsic enteric neurons and activated and/or sensitised by noxious stimuli such as heat $\left(>42^{\circ} \mathrm{C}\right)$, acidosis and several lipoxygenase products [31]. Stimulation of capsaicin-sensitive nerves in the rat stomach induces mast cell degranulation with subsequent hyperaemia [32] and capsaicin-sensitive nerves have been shown to exert a protective role during inflammation by the release of peripheral and central neuropeptides such as SP and CGRP [33, 34]. In fact, NK1 knock-out mice fail to develop neurogenic inflammation that is TRPV1 dependent [35]. This study has demonstrated that co-application of low concentration capsaicin with ATP can increase the activity in the pelvic nerve by $25.9 \%$ more than the sum of the individual responses. If capsaicin-sensitive neurons are important in the response to tissue injury, then it follows that ATP, itself released during tissue injury and noxious stimuli, should interact with the TRPV1 receptor. Previous studies have shown that ATP can enhance the effect of capsaicin on rat TRPV1-gated currents by acting as an allosteric factor [36]. Other evidence suggests that application of ATP to capsaicin-sensitive sensory neurons increases TRPV1-dependent SP release [37]. Also, ATP-induced thermal hyperalgesia is abolished in TRPV1 knock-out mice and this mechanism may involve the $\mathrm{P}_{2} \mathrm{Y}_{2}$ receptor [4]. In the present study, demonstrating that ATP can still activate pelvic nerve afferents during capsaicin-induced desensitisation may show an interesting aspect of the TRPV1 receptor. At a critical range of tissue concentrations, ligands may alter the sensitivity of the neuron to depolarise and this mechanism may impact upon the degree to which other mediators can stimulate these afferents in any given physiological situation. These capsaicin-sensitive nerve fibres may protect against stimulation from other mediators that is of a magnitude that may not actually be helpful.

The $\mathrm{pH}$ of tissues drops during inflammation and protons are known to sensitise and activate nociceptive neurons [38]. Some proton-gated ion channels or acid-sensing ion channels (ASICs) are exclusively expressed on primary afferent neurons [39] and both the expression and activity of these receptors can be altered by anti-inflammatory agents [40]. In addition, $\mathrm{P} 2 \mathrm{X}_{2}$ and $\mathrm{P} 2 \mathrm{X}_{2 / 3}$ receptors are $\mathrm{pH}$ 
sensitive [3]. In this study, protons were able to activate $53 \%$ of units that were responsive to ATP, a very similar proportion to capsaicin. At $\mathrm{pH} 6.8$, the activities of these units and a further $12 \%$ that responded to protons but not ATP, were over $40 \%$ higher than the sum of the responses to ATP and protons alone. At $\mathrm{pH} 6.5$, this percentage increase in activity had risen to $72.6 \%$. As the $\mathrm{pH}$ was lowered, an increasing percentage of units that were only responsive to protons contributed to the increased activity $(12 \%$ at $\mathrm{pH} 6.8$ and $21 \%$ at $\mathrm{pH} 6.5)$, suggesting two scenarios. Firstly, that the $\mathrm{pH}$ sensitive purinoceptors that were initially not activated became so as the concentration of protons increased. This seems unlikely, as some sort of response would have been expected in these units at the concentrations of ATP used $(1 \mathrm{mM})$. A more likely scenario is that when the $\mathrm{pH}$ is reduced, the presence of ATP is able to lower the threshold of TRPV1 receptors and therefore allow more of them to be activated by increasing concentrations of protons. Although ASICs undoubtedly play an important nociceptive role in an inflammatory environment, the TRPV1 receptor is key because it mediates an important protective response through the release of neuropeptides as well as transmitting other nociceptive information.

The role of ATP in regard to extrinsic afferents in inflammatory tissues is primarily as a signalling molecule, directly activating sensory neurons via $\mathrm{P} 2 \mathrm{X}$ and $\mathrm{P} 2 \mathrm{Y}$ receptors. The two different classes of receptors might mediate nociceptive function and its role in neurogenic inflammation respectively. We have also discussed a role for ATP as a neuromodulator acting at other receptors, facilitating their actions. Many of these mechanisms indicate that when there is a noxious stimulus that threatens tissue, extrinsic enteric sensory nerves are critical in communicating important nociceptive information to the central nervous system to influence other body systems and behaviour, in addition to orchestrating an ongoing local response that leads to protective vasoactive, secretory and immunological functions that eventually aid the healing process. There is now good evidence that ATP plays a role in both these processes.

\section{Acknowledgement}

The authors thank Dr. Gillian E. Knight for editorial assistance.

\section{Grants}

Funding for this project was provided by the Hamamelis Trust, Special Trustees of the Royal Free Hospital and Royal College of Surgeons of England.

\section{References}

1. Burnstock G. P2X receptors in sensory neurones. Br J Anaesth 2000; 84: 476-88.

2. Bradbury EJ, Burnstock G, McMahon SB. The expression of $\mathrm{P}_{2} \mathrm{X}_{3}$ purinoreceptors in sensory neurons: Effects of axotomy and glial-derived neurotrophic factor. Mol Cell Neurosci 1998; 12: 256-68.

3. Dunn PM, Zhong Y, Burnstock G. P2X receptors in peripheral neurones. Prog Neurobiol 2001; 65: 107-34.

4. Ruan H, Burnstock G. Localisation of $\mathrm{P}_{2} \mathrm{Y}_{1}$ and $\mathrm{P} 2 \mathrm{Y}_{4}$ receptors in dorsal root, nodose and trigeminal ganglia of the rat. Histochem Cell Biol 2003; 120: 415-26.

5. Burnstock G. Release of vasoactive substances from endothelial cells by shear stress and purinergic mechanosensory transduction. J Anat 1999; 194: 335-42.

6. Rong W, Spyer KM, Burnstock G. Activation and sensitisation of low and high threshold afferent fibres mediated by P2X receptors in the mouse urinary bladder. J Physiol 2002; 541: 591-600.

7. Rong W, Burnstock G. Activation of ureter nociceptors by exogenous and endogenous ATP in guinea pig. Neuropharmacology 2004; 47: 1093-101

8. Wynn G, Rong W, Xiang Z, Burnstock G. Purinergic mechanisms contribute to mechanosensory transduction in the rat colorectum. Gastroenterology 2003; 125: 1398-409.

9. Dimaline R, Dockray GJ. Multiple immunoreactive forms of vasoactive intestinal peptide in colonic mucosa. Gastroenterology 1978; 75: 387-92.

10. Bueno L, Fioramonti J, Delvaux M, Frexinos J. Mediators and pharmacology of visceral sensitivity; from basic to clinical investigations. Gastroenterology 1997; 112: 1714-43.

11. Roza C, Reeh PW. Substance P calcitonin gene-related peptide and $\mathrm{PGE}_{2}$ co-released from the mouse colon: A new model to study nociceptive and inflammatory responses in viscera in-vitro. Pain 2001; 93: 213-9.

12. Sitaraman SV, Merlin D, Wang L et al. Neutrophil-epithelial crosstalk at the intestinal luminal surface mediated by reciprocal secretion of adenosine and Il-6. J Clin Invest 2001; 107: 861-9.

13. Gershon MD. Serotonin and its implication for the management of irritable bowel syndrome. Rev Gastroenterol Disord 2003; 3: S25-34.

14. Holzer P. Gastrointestinal afferents as targets of novel drugs for the treatment of functional bowel disorders and visceral pain. Eur J Pharmacol 2001; 19: 177-93.

15. Page AJ, O’Donnell TA, Blackshaw LA. P2X purinoceptor-induced sensitization of ferret vagal mechanoreceptors in oesophageal inflammation. J Physiol 2000; 523: 403-11.

16. Paukert M, Osteroth R, Geisler HS et al. Inflammatory mediators potentiate ATP-gated channels through the $\mathrm{P}_{2} \mathrm{X}_{3}$ subunit. J Biol Chem 2001; 276: 21077-82.

17. Yiangou Y, Facer P, Baecker PA et al. ATP-gated ion channel $\mathrm{P} 2 \mathrm{X}_{3}$ is increased in human inflammatory bowel disease. Neurogastroenterol Motil 2001; 13: 365-9.

18. Wynn G, Ma B, Ruan HZ, Burnstock G. The purinergic component of mechanosensory transduction is increased in a rat model of colitis. Am J Physiol: Gastro Liver Physiol 2004; 287: G647-57.

19. Longhurst JC, Kaufman MP, Ordway GA, Musch TI. Effects of bradykinin and capsaicin on endings of afferent fibers from abdominal visceral organs. Am J Physiol 1984; 247: R552-9.

20. Hicks GA, Coldwell JR, Schindler M et al. Excitation of rat colorectal afferent fibres by 5-HT 3 receptors. J Physiol 2002; 5443: 861-9.

21. Lew WY, Longhurst JC. Substance, P 5-hydroxytryptamine and bradykinin stimulate abdominal visceral afferents. Am J Physiol 1986; 250: R465-73.

22. Yoshimura N, Seki S, Erickson KA et al. Histological and electrical properties of rat dorsal root ganglion neurons innervating the lower urinary tract. J Neurosci 2003; 23: 4355-61.

23. Blackshaw LA, Page AJ, Partosoedarso ER. Acute effects of capsaicin on gastrointestinal vagal afferents. Neuroscience 2000; 96: 407-16.

24. Kasai M, Mizumura K. Effects of $\mathrm{PGE}_{2}$ on neurons from rat dorsal root ganglia in intact and adjuvant-inflamed rats: Role of NGF on $\mathrm{PGE}_{2}$-induced depolarization. Neurosci Res 2001; 41: 345-53.

25. Petruska JC, Cooper BY, Gu JG et al. Distribution of $\mathrm{P} 2 \mathrm{X}_{1}, \mathrm{P} 2 \mathrm{X}_{2}$ and $\mathrm{P} 2 \mathrm{X}_{3}$ receptor subunits in rat primary afferents: Relation to population markers and specific cell types. J Chem Neuroanat 2000; 20: $141-62$. 
26. Moriyama $\mathrm{T}$, Iida $\mathrm{T}$, Kobayashi $\mathrm{K}$ et al. Possible involvement of $\mathrm{P}_{2} \mathrm{Y}_{2}$ metabotropic receptors in ATP-induced transient receptor potential vanilloid receptor 1-mediated thermal hypersensitivity. J Neurosci 2003; 23: 6058-62.

27. Stucky CL, Medler KA, Molliver DC. The P2Y agonist UTP activates capsaicin-sensitive cutaneous nociceptors. Pain 2004; 109: 36-44.

28. Kozlowski CM, Green A, Grundy D et al. The 5- $\mathrm{HT}_{3}$ receptor antagonist alosetron inhibits the colorectal distention induced depressor response and spinal c-fos expression in the anaesthetised rat. Gut 2000; 46: 474-80.

29. Schikowski A, Thewissen M, Mathis C et al. Serotonin type-4 receptors modulate the sensitivity of intramural mechanoceptive afferents of the cat rectum. Neurogastroenterol Motil 2002; 14: 217-9.

30. Barajas-Lopez C, Montano LM, Espinosa-Luna R. Inhibitory interactions between $5-\mathrm{HT}_{3}$ and $\mathrm{P} 2 \mathrm{X}$ channels in submucosal neurons. Am J Physiol: Gastro Liver Physiol 2002; 283: G1238-48.

31. Tominaga M, Caterina MJ, Malmberg AB et al. The cloned capsaicin receptor integrates multiple pain-producing stimuli. Neuron 1998; 21: $531-43$.

32. Wallace JL, McKnight GW, Befus AD. Capsaicin-induced hyperemia in the stomach: Possible contribution of mast cells. Am J Physiol 1992; 263: G209-14.

33. Green T, Dockray GJ. Characterization of the peptidergic afferent innervation of the stomach in the rat mouse and guinea-pig. Neuroscience 1988; 25: 181-93.

34. McVey DC, Vigna SR. The capsaicin VR1 receptor mediates substance $\mathrm{P}$ release in toxin A-induced enteritis in rats. Peptides 2001; 22: 1439-46.

35. Laird JM, Olivar T, Roza C et al. Deficits in visceral pain and hyperalgesia of mice with a disruption of the tachykinin NK1 receptor gene. Neuroscience 2000; 98: 345-52.

36. Kwak J, Wang MH, Hwang SW et al. Intracellular ATP increases capsaicin-activated channel activity by interacting with nucleotidebinding domains. J Neurosci 2000; 20: 8298-304.

37. Huang $\mathrm{H}, \mathrm{Wu} \mathrm{X}, \mathrm{Nicol} \mathrm{GD}$ et al. ATP augments peptide release from rat sensory neurons in culture through activation of $\mathrm{P} 2 \mathrm{Y}$ receptors. J Pharmacol Exp Ther 2003; 306: 1137-44.

38. Reeh PW, Steen KH. Tissue acidosis in nociception and pain. Prog Brain Res 1996; 113: 143-51.

39. Chen CC, England S, Akopian AN, Wood JN. A sensory neuronspecific proton-gated ion channel. Proc Natl Acad Sci USA 1998; 95: $10240-45$.

40. Voilley N, de Weille J, Mamet J, Lazdunski M. Nonsteroid antiinflammatory drugs inhibit both the activity and the inflammationinduced expression of acid-sensing ion channels in nociceptors. J Neurosci 2001; 21: 8026-33. 